Check for updates

Cite this: J. Mater. Chem. A, 2021, 9 , 4679

Received 5th December 2020
Accepted 9th February 2021

Received 5th December 2020
Accepted 9th February 2021

DOI: $10.1039 / d 0 t a 11821 d$

rsc.li/materials-a

\section{Controlling surface chemistry and mechanical properties of metal ionogels through Lewis acidity and basicity $\uparrow$}

\author{
Coby J. Clarke, (D) $\star^{\star a}$ Richard P. Matthews, (D) a Alex P. S. Brogan (D) ${ }^{b}$ \\ and Jason P. Hallett (iD ${ }^{a}$
}

\begin{abstract}
lonogels are emerging as soft materials with remarkable physical properties that can be tuned to suit application requirements. The liquid component-ionic liquids-are effectively involatile, which provides new opportunities to explore gel surfaces with UHV based analytical techniques. Here, we exploit the highly solvating nature of ionic liquids to fabricate poly(ethylene glycol) based ionogels with high concentrations of zinc, and then investigate their surfaces to show that tunability extends beyond the bulk to the interface. A unique relationship between Lewis acidity and basicity and the surface concentration of metal was revealed. Chemical state analysis and molecular dynamics showed that Lewis acidic metals templated polymers to give new architectures reduced brittleness and increased flexibility, while Lewis basic metals improved polymer uniformity and strengthened gels. Therefore, bulk structure, surface composition, and metal speciation were all found to be intimately related and dependent upon the coordination strengths of ionic liquid anions. Importantly, the highly controllable surface and structural properties of metal ionogels allow fine-tuning across a broad design space, which presents new opportunities for gel based applications.
\end{abstract}

Ionogels are a promising class of soft materials that are primarily composed of ionic liquids with cross-linked polymer networks. ${ }^{1}$ The properties of ionic liquids are well-known and arise from their ionic composition, ${ }^{2}$ which bestows unique properties that are unparalleled by molecular liquids. Consequently, the high ionic liquid content of ionogels integrate these properties into soft materials, providing remarkable

\footnotetext{
${ }^{a}$ Department of Chemical Engineering, South Kensington Campus, Imperial College London, Imperial College Road, Kensington, London SW7 2AZ, UK. E-mail: coby. clarke@nottingham.ac.uk

${ }^{b}$ Department of Chemistry, King's College London, Britannia House, London, SE1 1DB, $U K$

$\dagger$ Electronic supplementary information (ESI) available: Experimental details, additional discussions, XPS high resolution data, MD simulation details and results. See DOI: 10.1039/d0ta11821d

\$ Current address: GSK Carbon Neutral Laboratory, Jubilee Campus, University of Nottingham, Nottingham NG7 2 GA, UK.
}

material features that present new and unique opportunities. ${ }^{3}$ For example, ionogels are electrically conductive, heat stable, resistant to evaporation, non-flammable, and highly tunable. ${ }^{\mathbf{4}-6}$ The latter point is of particular importance because it arises from the extensive structural diversity of ionic liquids, ${ }^{7}$ and is enhanced by the large number of cross-linked polymer networks available. Hence, ionogels are versatile soft materials and the benefits of their tunability are far reaching, impacting areas such as drug-delivery, ${ }^{8}$ stimuli-responsive smart materials, ${ }^{9}$ and energy storage. ${ }^{\mathbf{1 0}}$

Understanding structure-property relationships in ionogels is important because a wide range of physical properties can be accessed through modular design of ionic liquids and polymers. Therefore, molecular level insights can help navigate the broad design space of ionogels to match physical and chemical properties to the application of interest, which is key to exploiting the benefits of ionic liquid based materials. Our previous study showed that the structure of cross-linked poly(ethylene glycol) diacrylate (PEGDA) could be controlled to influence the ratio of ionic liquid and polymer at the surfaces of ionogels. ${ }^{11}$ To the best of our knowledge, this was the first time ionogel outer surfaces had been studied and the findings showed that structure-property relationships extended beyond the bulk to the surface-an insight that was only possible because the low volatility of ionic liquids enable surfaces analysis with UHV-based analytical technicques, ${ }^{12}$ which is impossible for gels with volatile liquid phases.

Compared to other solvents, ionic liquids can dissolve large quantities of metal salts - up to $75 \mathrm{~mol} \%$, or $\chi_{0.75}$ - to give freeflowing solutions that are useful in catalytic, energy, or material applications. ${ }^{13-15}$ Even weakly coordinating ionic liquids can dissolve large quantities of metals. ${ }^{16}$ In the presence of functional coordinating groups, weakly coordinating anions undergo ligand exchange to give new interactions that improve or introduce new properties. ${ }^{17}$ For example, polyether chains can compete with weakly coordinating $\left[\mathrm{NTf}_{2}\right]^{-}$ligands to coordinate $\mathrm{Mg}^{2+}$, which improves the reversible electrochemical deposition/dissolution of magnesium and inhibits dendritic 
growth. ${ }^{18}$ Similar interactions can also be used to form pseudocrown ethers polymers, to give in-chain cavities capable of selective molecular recognition. ${ }^{19}$ Hence, the balance between interacting and non-interacting groups can be exploited in both ionic liquids and polymers, the two major components of ionogels. Hydrogel and organogel studies have shown that metals can introduce unusual new architectures to gel media, to give controllable porosity ${ }^{\mathbf{2 0}}$ and supramolecular organisation. ${ }^{21}$ Therefore, there is great interest in extending these investigations to ionogels, especially when considering that ionic liquids and polymers can both interact with embedded metals.

In this work, we have prepared ionogels from ionic liquids containing large quantities of dissolved zinc (33 mol\%). Highly cross-linked PEGDA was selected as the polymer phase, and [omim] Cl or [omim] $\left[\mathrm{NTf}_{2}\right]$ were chosen as the liquid phases as they contained strongly coordinating and weakly coordinating anions that gave Lewis basic and Lewis acidic metal complexes, respectively. ${ }^{22,23}$ Surface compositions of ionogels were investigated with a variety of surface analysis techniques and bulk structure was investigated with mechanical testing. A molecular level understanding of the complex interactions between the ionic liquid, polymer, and zinc was provided by molecular dynamics (MD). Coordination of polymers to Lewis acidic metal complexes gave new polymer architectures via templating, which reduced brittleness and increased flexibility of the gel and led to the metal being sequestered in the bulk. Conversely, Lewis basic metals complexes did not interact with polymer supports, but did reduce the hydrogen bonding acceptor ability of the anions to improve polymer uniformity and strengthen ionogels. Thus, herein we provide a detailed and comprehensive investigation of metal ionogels as highly tunable soft materials with several levels of control provided by metals, cations, anions, polymers, and, importantly, the competing behaviour of the collective components. The ability to study gel surface compositions not only impacts interfacial design, it also provides a window into the bulk which can help reveal new information that is otherwise hidden. The advantages of ionogel surfaces are quickly being realised, ${ }^{24}$ and new insights into surface composition can greatly improve current understanding at the molecular level to initiate the development of interfacially tuned gels.

\section{Results and discussion}

The first step in our study was to quantify [omim $]^{+}$ionogel surfaces without metal ions to understand whether long-chain ionic liquids followed the same trends as short-chain analogues. ${ }^{11}$ Therefore, XPS was used to analyse the top 7$9 \mathrm{~nm}$ (ref. 25) of both [omim] Cl and [omim] [ $\left.\mathrm{NTf}_{2}\right]$ ionogels with PEGDA content from $0-40 \mathrm{wt} \%$ (ESI, Fig. S1, Table S3 and S4†) over a grid of five sites to account for surface inhomogeneity and measurement error. We chose to prepare ionogels from long chain ionic liquids primarily for internal charge correction of photoelectron spectra, ${ }^{\mathbf{2 6}}$ which was important for accurate chemical state analysis in mixtures of non-conductive polymer and conductive ionic liquids (i.e. differential surface charging). ${ }^{27}$ The XPS derived N/O ratios for [omim]Cl ionogels showed a large decrease from 16.6 to 6.5 when increasing the PEGDA content from 5-40 wt\%. However, there was only a small amount of oxygen at the surface- 1.8 at\% for $40 \mathrm{wt} \%$ PEGDAwhich demonstrated that [omim] Cl ionogels surfaces were ionic liquid rich. In our previous work, ${ }^{11}$ we showed that short-chain ionic liquids with high basicity anions ${ }^{28}$ such as $\mathrm{Cl}^{-}$gave polymer-rich ionogel surfaces as a result of dense polymer bundles formed from poor solvent-monomer mixing. Increasing the length of the aliphatic chain appeared to disrupt this surface trend, which was likely to be due to a combination of aliphatic chain surface enrichment ${ }^{29}$ and improved miscibility of the ionic liquid with PEGDA. ${ }^{30}$ The surfaces of [omim] $\left[\mathrm{NTf}_{2}\right]$ ionogel were also found to be rich in ionic liquid (ESI, Fig. S1b $\dagger$ ) with very little polymer present, which matched those of short chain ionogels analogues (ESI, Table S5†). Therefore, [omim] Cl and [omim] $\left.\mathrm{NTf}_{2}\right]$ ionogels both had ionic liquid rich surfaces (in the top $9 \mathrm{~nm}$ ) that were chemically different, but compositionally similar.

We then looked to investigate ionogel surfaces prepared with metal containing ionic liquids. Zn was chosen as an archetypal metal because it is diamagnetic with a closed d-orbital, which has been shown to give sharp, intense photoemission signals ideal for XPS. ${ }^{22}$ Concentrations of $\chi_{\mathrm{Zn}[\mathrm{A}] 2}=0.33$ (33 mol\%) were used because speciation in the control ionic liquids is well known; in $\left[\right.$ omim]Cl the Lewis basic $\left[\mathrm{ZnCl}_{4}\right]^{2-}$ anion is present, ${ }^{31}$ while in $[\mathrm{omim}]\left[\mathrm{NTf}_{2}\right]$ the Lewis acidic $\left[\mathrm{Zn}\left(\mathrm{NTF}_{2}\right)_{6}\right]^{4-}$ anion is present. ${ }^{13,32}$ The resulting solutions of [omim] $\mathrm{Cl}_{-}{ }_{0.33^{-}}$ $\mathrm{ZnCl}_{2}$ and $[\mathrm{omim}]\left[\mathrm{NTf}_{2}\right]{ }_{0.33} \mathrm{Zn}\left[\mathrm{NTf}_{2}\right]_{2}$ were used to prepare $30 \mathrm{wt} \%$ PEGDA ionogels, which were free-standing, clear gels. Parallel angle resolved XPS (PARXPS) was then used to depth profile (ESI, Fig. S2a-d $\dagger$ ) the ionic liquids controls and $30 \mathrm{wt} \%$ PEGDA ionogels from $8.2 \mathrm{~nm}$ to $2.4 \mathrm{~nm}$ to investigate $\mathrm{Zn}$ concentrations towards the outer surface. For strongly coordinating $\mathrm{Cl}^{-}$anions, $\mathrm{Zn}$ was observed at all depths in both the ionic liquid and the ionogel (Fig. 1a and b). A small decrease in the quantity of $\mathrm{Zn}$ at $2.4 \mathrm{~nm}$ was observed in the ionogel relative to the pure ionic liquid ( 0.31 at\% less), with a concurrent increase in [omim $]^{+}$cations. The FWHM and binding energies values of the $\mathrm{Zn} 2 \mathrm{p}_{3 / 2}$ photoemissions differed only by $0.1 \mathrm{eV}$ at most, which indicated that the chemical state of $\mathrm{Zn}$ was unaffected by PEGDA polymer and $\left[\mathrm{ZnCl}_{4}\right]^{2-}$ remained intact. This was confirmed by the $\mathrm{Cl} 2 \mathrm{p}$ photoemission, which showed a single chemical state for chlorine (Fig. 1e). Altogether, these observations showed that metal speciation was unaffected in ionogels when strongly coordinating anions were present. The ionogel surface was primarily composed of ionic liquid-also supported by the weak oxygen signal-but small changes in the $\mathrm{N} / \mathrm{Zn}$ ratio (ESI, Fig. S3 $\dagger$ ) implied that the top $8.2 \mathrm{~nm}$ was reordered (relative to the control ionic liquid), possibly by association of $\left[\mathrm{ZnCl}_{4}\right]^{2-}$ to PEGDA or segregation of $[\mathrm{omim}]^{+}$ from PEGDA.

PARXPS of the $\left[\mathrm{NTf}_{2}\right]^{-}$containing ionic liquid showed that Zn was present at all depths; however, the $30 \mathrm{wt} \%$ PEGDA ionogel showed no $\mathrm{Zn}$ at any depth, even down to $8.2 \mathrm{~nm}$ (Fig. 1c and d). The surface of the ionogel was found to primarily contain [omim] $\left[\mathrm{NTf}_{2}\right]$ ionic liquid and all photoemission binding energies matched those of metal free $[\mathrm{omim}]\left[\mathrm{NTf}_{2}\right]$ 
(a)

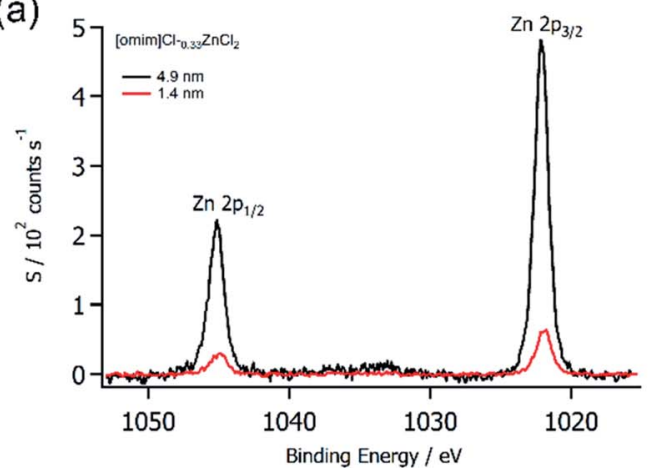

(c)

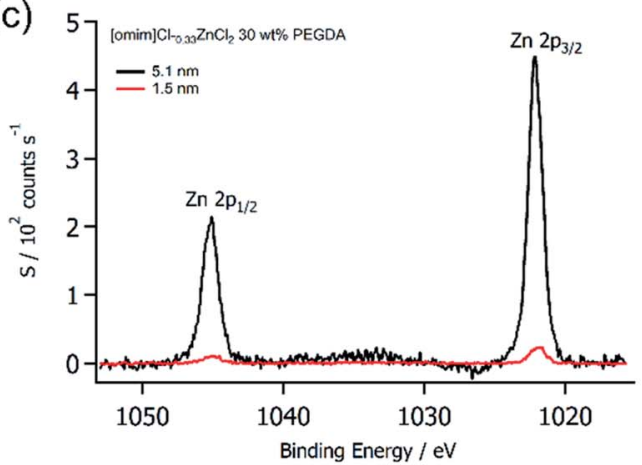

(e)

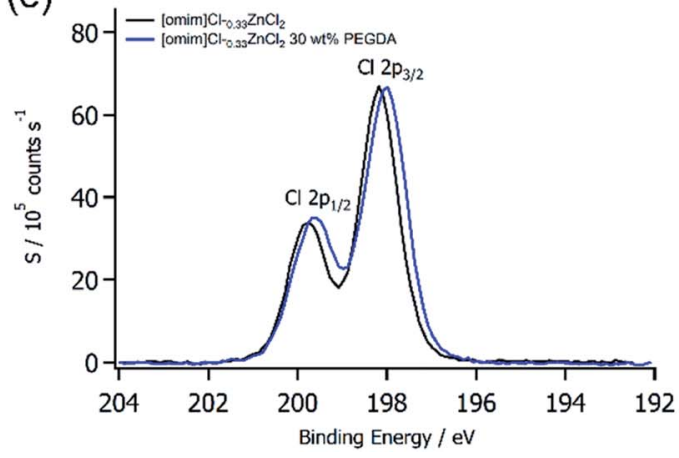

(b)

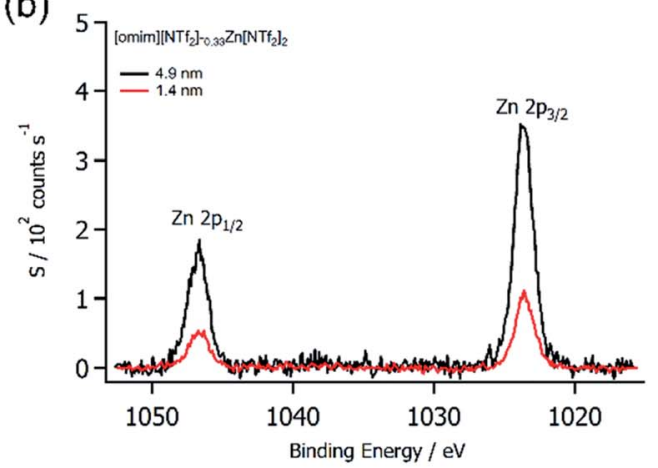

(d)
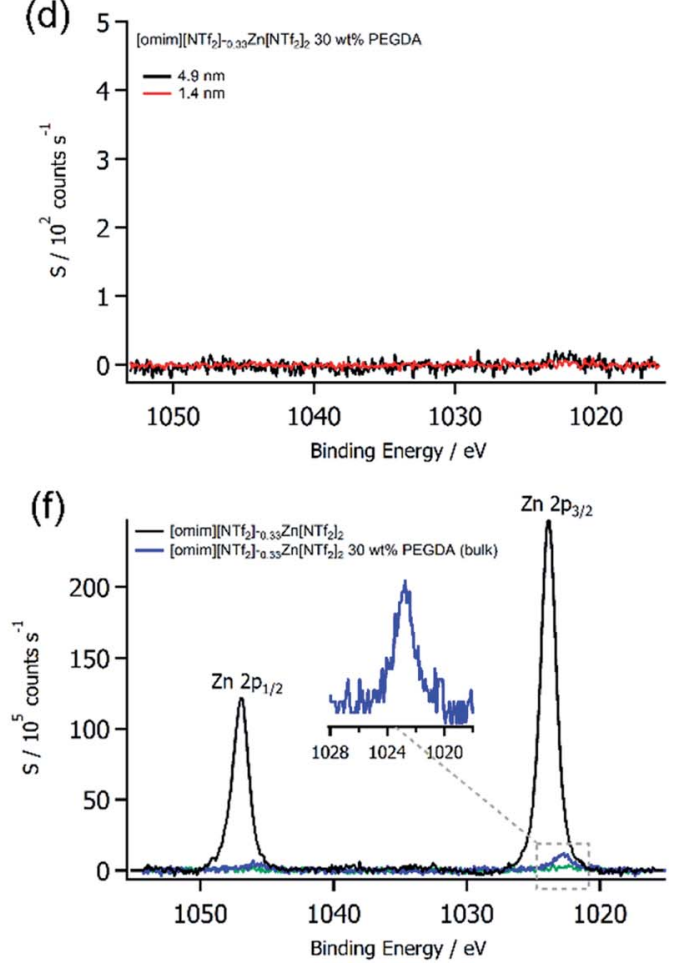

Fig. 1 PARXPS Zn 2p high resolution scans for (a) [omim]Cl-o.33 $\mathrm{ZnCl}_{2}$, (b) [omim] $\left[\mathrm{NTf}_{2}\right]-{ }_{0.33} \mathrm{Zn}[\mathrm{NTf}]_{2}$, (c) $[\mathrm{omim}] \mathrm{Cl}-0.33 \mathrm{ZnCl} 2$ with $30 \% \mathrm{PEGDA}$, and (d) [omim] $\left[\mathrm{NTf}_{2}\right]-{ }_{0.33} \mathrm{Zn}\left[\mathrm{NTf}_{2}\right]_{2}$ with $30 \%$ PEGDA. Two signals are shown for $25^{\circ}$ (black) and $75^{\circ}$ (red) emission angles with the corresponding depths on respective plots. (e) XPS $\mathrm{Cl} 2 \mathrm{p}$ high resolution scans of [omim] Cl- $0.33 \mathrm{ZnCl}_{2}$ (black) and [omim] $\mathrm{Cl}-{ }_{0} .33 \mathrm{ZnCl} 2$ with 30 wt\% $\mathrm{PEGDA}$ (blue). (f) XPS Zn $2 p$ high resolution scans of [omim] $\left[N T f_{2}\right]-{ }_{0.33} Z n\left[N T f_{2}\right]_{2}$ (black) and bulk [omim] $\left[N T f_{2}\right]-{ }_{0.33} Z n\left[N T f_{2}\right]$ with 30 wt\% PEGDA (blue).

with $30 \mathrm{wt} \%$ PEGDA. Relative to the $\mathrm{Cl}^{-}$ionic liquid, the $\left[\mathrm{NTf}_{2}\right]^{-}$ ionic liquid gave $\mathrm{Zn} 2 \mathrm{p}_{3 / 2}$ binding energies $1.7 \mathrm{eV}$ higher, which highlighted that $\mathrm{Zn}$ had a significantly lower electron density when coordinated by $\left[\mathrm{NTf}_{2}\right]^{-}$anions. A Zn 2p binding energy was obtained for the $[\mathrm{omim}]\left[\mathrm{NTf}_{2}\right]-{ }_{0.33} \mathrm{Zn}\left[\mathrm{NTf}_{2}\right]$ ionogel by removing the top 1-2 mm of the gel with a scalpel (Fig. 1f). The $\mathrm{Zn} 2 \mathrm{p}_{3 / 2}$ binding energy of the ionogel was $1.1 \mathrm{eV}$ lower than the binding energy measured for $\mathrm{Zn}$ in pure [omim] $\left[\mathrm{NTf}_{2}\right]-{ }_{0.33} \mathrm{Zn}$ $\left[\mathrm{NTf}_{2}\right]_{2}$ ionic liquid, which indicated that $\mathrm{Zn}$ had gained a significant amount of electron density when incorporated into the gel. Therefore, we hypothesised that the polyether groups of PEGDA had displaced weakly coordinating $\left[\mathrm{NTf}_{2}\right]^{-}$ligands of the Lewis acidic complex, which could explain the observed gain in electron density and resulting binding energy shift. This ligand substitution led to $\mathrm{Zn}$ being sequestered in the bulk ionogel, where coordination to PEGDA could cause conformational changes in the polymer chains. Pseudo-crown ether formation can result from these interactions if polymer chains match the cation's size. ${ }^{19}$ However, the PEGDA used in this work $(\mathrm{MW}=575)$ had an average length of 10-11 monomer units, which was far too long for pseudo-crown ethers to form. Nevertheless, molecular scale conformational changes could cause macroscopic structural changes, which could ultimately affect gel properties. Recent reports have shown that $\left[\mathrm{NTf}_{2}\right]^{-}$ ligands can be substituted by functional groups attached to cations, ${ }^{33}$ which supported our coordination hypothesis. Furthermore, strongly coordinating ligands such as $\mathrm{Cl}^{-}$were unlikely to be substituted by polyether groups, which could explain why $[\mathrm{omim}] \mathrm{Cl}^{-}{ }_{0.33} \mathrm{ZnCl}_{2}$ ionogels had $\mathrm{Zn}$ at the surface and speciation was unaffected. 
Deconvoluting photoemission signals is difficult in XPS, ${ }^{12}$ which complicates quantifications of components that share a common element, such as oxygen containing $\left[\mathrm{NTf}_{2}\right]^{-}$and PEGDA. Therefore, ionogels were investigated with secondary ion mass spectrometry (SIMS) depth profiling to understand the spatial arrangement of chemical species at the surface, and for definitive identification of molecular species during sputtering. SIMS of metal free [omim] $\left[\mathrm{NTf}_{2}\right]$ ionogel with $30 \mathrm{wt} \%$ PEGDA showed that small amounts of polymer were present in the outer 2-3 nm (ESI, Fig. S4 $\dagger$ ), and that depth profiling of ionogels was possible as both ionic liquid and polymer components could be identified and monitored by MS. The surface of the [omim] $\mathrm{Cl}^{-}{ }_{0.33} \mathrm{ZnCl}_{2}$ ionogel with $30 \%$ PEGDA was found to be rich in $\mathrm{Zn}$, while the surface of the $\left[\mathrm{NTf}_{2}\right]^{-}$ionogel analogue had a large depletion of $\mathrm{Zn}-\mathrm{a}$ factor of 38 lower than the $\mathrm{Cl}^{-}$ionogel (Fig. 2). The $\mathrm{Cl}^{-}$ionogel showed relatively high and consistent ionic liquid and $\mathrm{Zn}$ signals throughout depth profiling, with a steady increase in PEGDA. Conversely, the $\left[\mathrm{NTf}_{2}\right]^{-}$ionogel had lower levels of PEGDA at the outer surface which significantly increase as sputtering proceeded (by a factor of 67), while the amount of ionic liquid steadily decreased. Small fluctuations in the PEGDA signal were also mirrored by the $\mathrm{Zn}$ signal, which demonstrated that $\mathrm{Zn}$ was no longer associated with the ionic liquid but PEGDA instead. This validated the low binding energy of Zn observed in XPS analysis and supported the hypothesis that $\mathrm{Zn}$ was coordinated to PEGDA, which displaced the weakly coordinating $\left[\mathrm{NTf}_{2}\right]^{-}$ligands. A similar surface depletion of Co in a $30 \mathrm{wt} \%$ PEGDA ionogel (i.e. [omim $]\left[\mathrm{NTf}_{2}\right]-{ }_{0.33} \mathrm{Co}\left[\mathrm{NTf}_{2}\right]_{2}$ ) was also observed (ESI, Fig. S5 $\dagger$ ), which confirmed that surface depletion was not unique to $\mathrm{Zn}$ and that other weakly coordinated metals were subject to similar effects. In addition, control samples of ionic liquid showed no variation in the metal concentration during depth profiling of the liquid surface (ESI, Fig. S5 $\dagger$ ), which confirmed that PEGDA was responsible for sequestering of metals within the bulk ionogels.

The results obtained from surface analysis suggested that there was a balance between ionic liquid and polymer coordination to $\mathrm{Zn}$, which was influenced by the Lewis acidity/basicity of the metal complex. We wanted to investigate how the bulk properties of ionogels changed as this balanced was tipped, which was particularly important when considering that conformational changes in PEGDA were likely to result from metal coordination. In line with previous reports, here we use compressive stress-strain data as being representative of ionogel bulk structure, ${ }^{11}$ (ESI, Fig. S6 $\dagger$ ) and thus an indication of polymer structure. Our first goal was to mechanically characterise metal free ionogels of long-chain [omim] Cl and [omim] $\left[\mathrm{NTf}_{2}\right]$ to provide a reliable basis for comparison (ESI, Table $\mathrm{S} 10 \dagger)$. The mechanical properties of [omim]Cl ionogels were similar to those previously published for short-chain [emim] [OAc] ionogels. ${ }^{11}$ The $[\mathrm{OAc}]^{-}$anion has a high basicity similar to that of $\mathrm{Cl}^{-},{ }^{34}$ so the mechanical similarity was expected given the previously observed link between anion basicity and PEGDA structure. ${ }^{11}$ The PEGDA polymer structure of [omim] Cl ionogels were therefore composed of loosely interconnected bundles of polymer, which resulted in relatively weak gels. Bulk behaviour of the $\mathrm{Cl}^{-}$and $[\mathrm{OAc}]^{-}$systems were the same, despite the observed differences in surface composition, which could be explained by alkyl chain enrichment at the ionogel surface in vacuo. The mechanical properties of low basicity [omim] $\left[\mathrm{NTf}_{2}\right]$ ionogels matched those of short-chain [emim] $\left[\mathrm{NTf}_{2}\right]$ and [bmim] $]\left[\mathrm{NTf}_{2}\right]$, which confirmed that the bulk structure was composed of uniform networks of polymer.

For $\mathrm{Cl}^{-}$anions, the addition of $\mathrm{Zn}$ to the ionogel increased both failure stress and strain, which improved strength and toughness. The failure stress of the $[\mathrm{omim}] \mathrm{Cl}_{2}-{ }_{0.33} \mathrm{ZnCl}_{2}$ ionogel

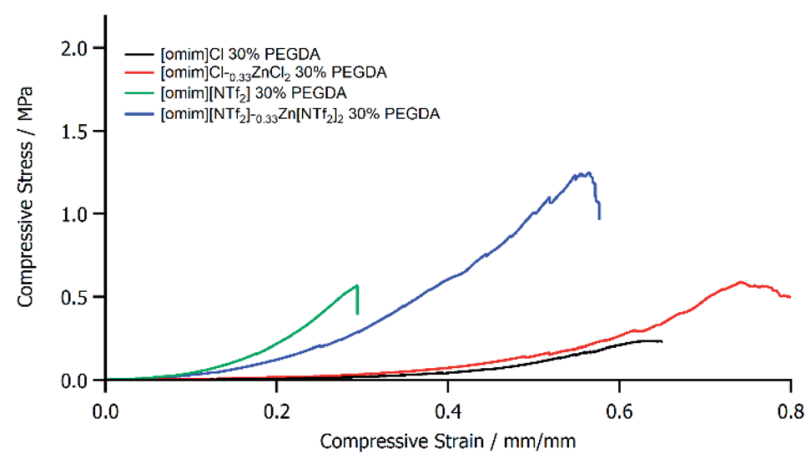

Fig. 3 Plots of compressive stress against compressive strain for ionogels of [omim] Cl (black), [omim] Cl- ${ }_{0.33} \mathrm{ZnCl}_{2}$ (red), [omim] $\left[\mathrm{NTf}_{2}\right.$ ] (green), and [omim] $\left[\mathrm{NTf}_{2}\right]-{ }_{0.33} \mathrm{Zn}\left[\mathrm{NTf}_{2}\right]_{2}$ (blue) with 30\% PEGDA. (a)

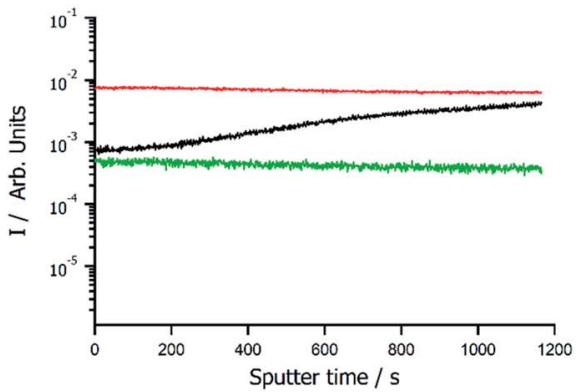

(b)

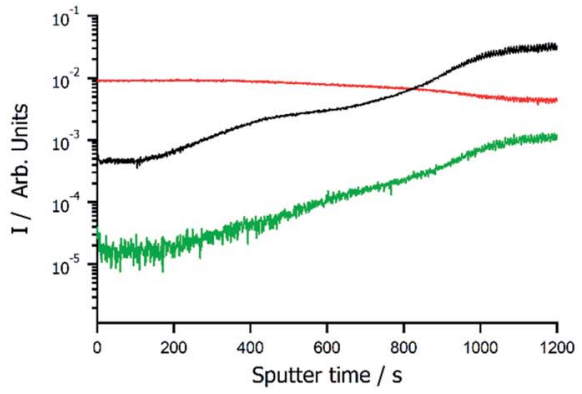

Fig. 2 SIMS depth profiles of ionogels composed of (a) [omim] Cl $-{ }_{0.33} \mathrm{ZnCl}_{2}$ with $30 \%$ PEGDA and (b) [omim] $\left[\mathrm{NTf} \mathrm{f}_{2}\right]-{ }_{0.33} \mathrm{Zn}[\mathrm{NTf}]_{2}$ with $30 \%$ PEGDA, showing the lomim] $^{+}$cation (red), PEGDA (black), and zinc (green). 
Table 1 Compressive modulus at low $(<10 \%)$ and high (before fracture) strain and failure stress for [omim] Cl, [bmim] [NTf 2 ], [omim] [NTf $f_{2}$, [omim] $\mathrm{Cl}-{ }_{0.33} \mathrm{ZnCl}_{2}$ and $[0 \mathrm{mim}]\left[\mathrm{NTf}_{2}\right]-{ }_{0.33} \mathrm{Zn}\left[\mathrm{NTf}_{2}\right]_{2}$ ionogels with $30 \mathrm{wt} \%$ PEGDA

\begin{tabular}{|c|c|c|c|c|c|}
\hline [omim]Cl & 30 & $0.065 \pm 0.0077$ & $1.32 \pm 0.20$ & $0.24 \pm 0.01$ & $58.39 \pm 2.77$ \\
\hline$[\mathrm{bmim}]\left[\mathrm{NTf}_{2}\right]$ & 30 & $1.23 \pm 0.13$ & $4.36 \pm 0.10$ & $0.61 \pm 0.10$ & $37.51 \pm 7.17$ \\
\hline$[\mathrm{omim}]\left[\mathrm{NTf}_{2}\right]$ & 30 & $1.71 \pm 0.20$ & $4.66 \pm 0.20$ & $0.64 \pm 0.08$ & $33.33 \pm 4.90$ \\
\hline$[\mathrm{omim}]\left[\mathrm{NTf}_{2}\right]-{ }_{0.33} \mathrm{Zn}\left[\mathrm{NTf}_{2}\right]_{2}$ & 30 & $0.77 \pm 0.14$ & $2.99 \pm 0.39$ & $0.87 \pm 0.28$ & $52.65 \pm 1.68$ \\
\hline
\end{tabular}

was approximately 2.6 times the value of the metal free analogue (Fig. 3, Table 1) at both low and high strain. The change in anion from $\mathrm{Cl}^{-}$to $\left[\mathrm{ZnCl}_{4}\right]^{2-}$ resulted in a decreased hydrogen bond acceptor ability, ${ }^{22}$ which subsequently increased the strength of the gel by improving the uniformity of the polymer network, in line with the observations made in our previous work. ${ }^{11}$ The interaction of the metal with the ionic liquid therefore altered the physicochemical properties of the ionic liquid phase, which had an indirect impact on the structural properties of the polymer phase. Conversely, $\mathrm{Zn}$ reduced the brittleness of stiff $\left[\mathrm{NTf}_{2}\right]^{-}$ionogels, which increased the failure stress and failure strain and significantly increased the toughness. However, the modulus of the $\left[\mathrm{NTf}_{2}\right]^{-}$ionogel decreased on addition of $\mathrm{Zn}$ because the increase in strength was surpassed by a large increase in flexibility. The reduced brittleness and improved flexibility was apparent when handling the ionogels and it suggested that the highly uniformity polymer phase found in $\left[\mathrm{NTf}_{2}\right]^{-}$ionogels was disrupted. This observation was consistent with the previous hypothesis that $\mathrm{Zn}$ was coordinated to PEGDA. Furthermore, the decrease in compressive modulus for [omim] $\left[\mathrm{NTf}_{2}\right]-{ }_{0.33} \mathrm{Zn}\left[\mathrm{NTf}_{2}\right]_{2}$ ionogels could not be explained by basicity changes (further discussion in the ESI $\dagger$ ). These results highlighted that $\mathrm{Zn}$ could modulate ionogel mechanical properties through two different mechanisms-either indirectly, by altering the basicity of the ionic liquid anion, or directly, by coordinating PEGDA. $\mathrm{Cl}^{-}$and $\left[\mathrm{NTf}_{2}\right]^{-}$ionogels are examples of weak and strong gels respectively, and a wide range of mechanical properties exist between the two. Therefore, addition of $\mathrm{Zn}$ salts can allow intermediate properties to be obtained, which introduces a way to fine-tune the strength of ionogels across a broad design space to target application requirements.

Overall, mechanical testing showed that $\mathrm{Zn}$ could have considerable and opposing effects on ionogel toughness. We wanted to test our hypothesis that Zn-PEGDA coordination was responsible for reducing strength in $\left[\mathrm{NTf}_{2}\right]^{-}$ionogels, and to what degree polymer dimensions were affected. Therefore, MD simulations were used to investigate mixtures of PEGDA with [omim]Cl, [omim] $\left[\mathrm{NTf}_{2}\right]$, and their $\mathrm{Zn}$ analogues. The size of PEGDA polymers were quantified with three ensemble average parameters (Table 2), which were the radius of gyration $\left(R_{\mathrm{g}}\right)$, end-to-end distance $(R)$, and solvent accessible surface area (SASA), for three different concentrations of PEGDA (ESI, Table S11; Fig. S33 $\dagger$ ). The metal-free control ionic liquids mixtures showed that PEGDA was slightly smaller in high basicity $\mathrm{Cl}^{-}$ ionic liquids compared to low basicity $\left[\mathrm{NTf}_{2}\right]^{-}$ionic liquids, which was consistent with previous SANS experiments. ${ }^{11}$ Addition of Zn did not effect PEGDA size for the $\mathrm{Cl}^{-}$containing ionic liquid; however, addition of $\mathrm{Zn}$ to $\left[\mathrm{NTf}_{2}\right]^{-}$ionic liquids caused a significant reduction in all three parameters, which indicated that PEGDA polymer chains had contracted in size. For example, the $R$ value of PEGDA in [omim] $\left[\mathrm{NTf}_{2}\right]-{ }_{0.33} \mathrm{Zn}\left[\mathrm{NTf}_{2}\right]_{2}$ reduced by $29.3 \%$ relative to the $[\mathrm{omim}]\left[\mathrm{NTf}_{2}\right]$ control (IL/ PEGDA $=30$ ). Larger amounts of $\mathrm{Zn}$ caused larger contractions in the polymer size for $[\mathrm{omim}]\left[\mathrm{NTf}_{2}\right]-{ }_{0.33} \mathrm{Zn}\left[\mathrm{NTf}_{2}\right]_{2}$, but the analogous [omim] $\mathrm{Cl}^{-}{ }_{0.33} \mathrm{ZnCl}_{2}$ mixtures showed that polymer size was independent of the Zn/PEGDA ratio.

Table 2 Ensembled average radius of gyration $\left(R_{\mathrm{g}}\right)$, end-to-end distance $(R)$, and solvent accessible surface area (SASA) for PEGDA monomers in metal-free [omim] Cl and [omim] $\left[\mathrm{NTf}_{2}\right]$, and $\mathrm{Zn}$ containing [omim] $\mathrm{Cl}-0.33 \mathrm{ZnCl}_{2}$ and $[0 \mathrm{mim}]\left[\mathrm{NTf} \mathrm{f}_{2}\right]-0.33 \mathrm{Zn}\left[\mathrm{NTf}_{2}\right]_{2}$

\begin{tabular}{|c|c|c|c|c|c|}
\hline Ionogel & IL/PEGDA & Zn/PEGDA & $R_{\mathrm{g}} / \AA$ & $R / \AA$ & SASA $/ \AA^{2}$ \\
\hline \multirow[t]{2}{*}[\mathrm{omim}]{$\mathrm{Cl}$} & 30 & 0 & $7.1 \pm 1.1$ & $16.8 \pm 5.5$ & $631.2 \pm 29.3$ \\
\hline & 10 & 0 & $7.3 \pm 1.3$ & $17.6 \pm 5.8$ & $634.3 \pm 29.5$ \\
\hline \multirow[t]{3}{*}[\mathrm{omim}]{$\left[\mathrm{NTf}_{2}\right]$} & 30 & 0 & $7.4 \pm 1.2$ & $18.4 \pm 5.9$ & $638.7 \pm 28.1$ \\
\hline & 10 & 0 & $7.4 \pm 1.3$ & $18.2 \pm 6.2$ & $637.4 \pm 29.3$ \\
\hline & 6 & 0 & $7.4 \pm 1.3$ & $18.1 \pm 6.0$ & $636.6 \pm 29.6$ \\
\hline & 6 & 1.0 & $7.3 \pm 1.3$ & $17.8 \pm 5.9$ & $633.1 \pm 30.1$ \\
\hline \multirow[t]{3}{*}[\mathrm{omim}]{$\left[\mathrm{NTf}_{2}\right]_{0.33} \mathrm{Zn}\left[\mathrm{NTf}_{2}\right]_{2}$} & 30 & 5.0 & $5.3 \pm 0.5$ & $13.0 \pm 3.1$ & $538.8 \pm 16.5$ \\
\hline & 10 & 1.7 & $5.9 \pm 0.7$ & $15.0 \pm 4.2$ & $567.5 \pm 22.8$ \\
\hline & 6 & 1.0 & $6.1 \pm 0.9$ & $15.3 \pm 4.6$ & $576.2 \pm 24.8$ \\
\hline
\end{tabular}


(a)

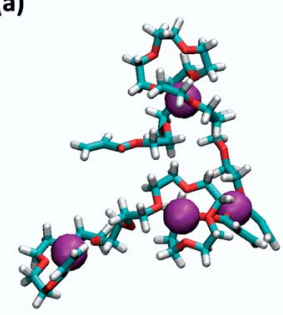

(c)

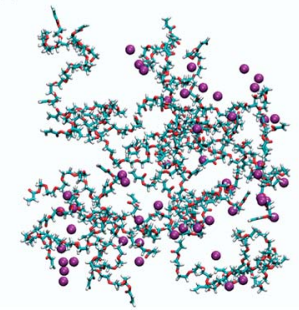

(b)

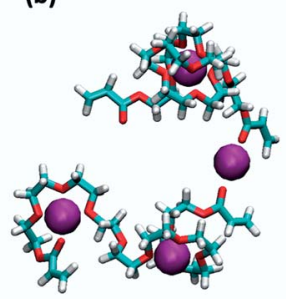

(d)

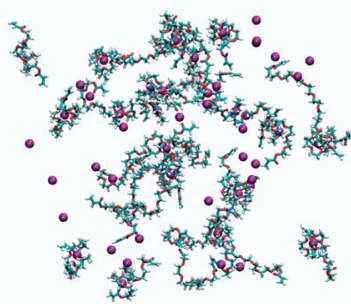

Fig. 4 (a and b) Zn ions in [omim] $\left[\mathrm{NTf}_{2}\right]-{ }_{0.33} \mathrm{Zn}\left[\mathrm{NTf}_{2}\right]_{2}$ showing (a) different coordination modes of $Z n$ ions to PEGDA present throughout the simulations and (b) dynamic and complex coordination states of multiple PEGDA monomers bound to $\mathrm{Zn}$ ions ( $40 \mathrm{~ns}$ simulation time for PEGDA/Zn ratio of 1). (c and d) Representative snapshots of $Z n$ and PEGDA taken from MD simulations of (c) [omim] $\mathrm{Cl}-0.33 \mathrm{ZnCl}_{2}$ and (d) [omim] $\left[\mathrm{NTf}_{2}\right]-{ }_{0.33} \mathrm{Zn}\left[\mathrm{NTf}_{2}\right]_{2}$

The contraction in polymer dimensions in [omim] [NTf2] $-{ }_{0.33} \mathrm{Zn}\left[\mathrm{NTf}_{2}\right]_{2}$ was confirmed to be the result of extensive Zn-O(PEGDA) interactions (Fig. 4). For example, the radial distribution functions (RDFs) for $\mathrm{Zn}-\mathrm{O}$ (PEGDA) in [omim] [NTf2] $-{ }_{0.33} \mathrm{Zn}\left[\mathrm{NTf}_{2}\right]_{2}$ had $g(r)$ values of $\approx 100-250$ (ESI, Fig. S27 $\dagger$ ), which were far higher than those obtained from [omim] $\mathrm{Cl}_{-0.33} \mathrm{ZnCl}_{2}$ which were $\approx 0-11$ (ESI, Fig. S28†). Furthermore, several coordination modes and monomer conformations were observed in the $\left[\mathrm{NTf}_{2}\right]^{-} \mathrm{Zn}$ mixtures, such as coiling (Fig. 4a) and bridging (Fig. 4b). Simulations also showed that $\mathrm{Zn}-\mathrm{Cl}$ interactions were far stronger than $\mathrm{Zn}$ $\mathrm{O}\left(\left[\mathrm{NTf}_{2}\right)\right.$ and $\mathrm{Zn}-\mathrm{N}\left(\left[\mathrm{NTf}_{2}\right)\right.$ interactions (ESI, Fig. S27 and S28 $\left.\dagger\right)$, which confirmed that the two anions had considerably different coordination strengths. Therefore, $\left[\mathrm{ZnCl}_{4}\right]^{2-}$ remained intact in the presence of PEGDA - validated by the solvation number $n(r)$ $=3.9-$ which limited direct $\mathrm{Zn}-\mathrm{O}(\mathrm{PEGDA})$ interactions in [omim] $\mathrm{Cl}_{-}{ }_{0.33} \mathrm{ZnCl}_{2}$ mixtures, whereas $\left[\mathrm{NTf}_{2}\right]^{-}$ligands were displaced to form new $\mathrm{Zn}-\mathrm{O}(\mathrm{PEGDA})$ coordination complexes in [omim $]\left[\mathrm{NTf}_{2}\right]-{ }_{0.33} \mathrm{Zn}\left[\mathrm{NTf}_{2}\right]_{2}$ mixtures.

Hydrogen bonding in imidazolium ionic liquids primarily occurs through the aromatic proton of the cationic ring. ${ }^{35}$ Strongly interacting anions form strong hydrogen bonds with these positions, while weakly interacting anions do not. Therefore, hydrogen bonding to solutes may increase for ionic liquids with weakly interacting anions because they do not compete for hydrogen bonds. Hydrogen bonding between aromatic ionic liquid cations and the oxygen atoms of polyethers have been identified as important solvent-solute interactions that influence miscibility and dissolution of polyethers in ionic liquids. ${ }^{36}$ However, our MD simulations showed that $[\mathrm{omim}]^{+}$ring protons weakly interacted with the oxygen atoms

of PEGDA and formed preferential interactions with ionic liquid anions instead (ESI Fig. S29†), for both $\mathrm{Cl}^{-}$and $\left[\mathrm{NTf}_{2}\right]^{-}$. The $[\text { omim }]^{+}-\mathrm{Cl}$ - interaction was found to be stronger than the $[\mathrm{omim}]^{+}-\mathrm{O}\left(\left[\mathrm{NTf}_{2}\right]^{-}\right)$interaction (ESI, Fig. S30†), which was consistent with previous results for ionic liquids. ${ }^{37}$ Alkyl chains weakly interacted in all systems (ESI, Fig. S31†) and alkylPEGDA interactions were found to be the weakest observed interactions (ESI, Fig. S32 $\dagger$ ), which supported that PEGDA structure was primarily determined by anion Lewis basicity/ acidity and the presence of $\mathrm{Zn}$.

MD simulations supported the observed changes in chemical state by XPS and confirmed the hypothesis that $\mathrm{Zn}$ was sequestered in the bulk by coordination to PEGDA for $\left[\mathrm{NTf}_{2}\right]^{-}$ ionic liquids. The considerable contraction in polymer size and the multiple coordination modes of $\mathrm{Zn}$ to PEGDA also supported the increase in flexibility and decrease in brittleness observed during compression testing. Chelation of the PEGDA chains around $\mathrm{Zn}$ decreases polymer uniformity and promotes disorder, which decreases stiffness and makes the ionogels more suitable for mechanically demanding applications. Furthermore, [omim] $\mathrm{X}-{ }_{0.33} \mathrm{Zn}[\mathrm{X}]_{2}$ ionogels with $30 \%$ PEGDA have approximate $\mathrm{Zn} / \mathrm{PEGDA}$ values of 1 . The results obtained from MD simulations suggest that larger quantities of $\mathrm{Zn}$ can have significantly larger reductions on polymer size, and therefore, mechanical strength. This can be readily achieved because of the highly solvating nature of ionic liquids $\left(\geq \chi_{0.75}\right.$ is possible), which is one of the unique properties that extend to ionogels to make them exceptional soft materials.

Following the investigation of surface and bulk inhomogeneity in $\mathrm{Zn}$ ionogels, we decided to thermally characterise the ionic liquids and gel materials prepared in this work (ESI, Table $\mathrm{S} 12 \dagger$ ) as thermal properties are critical for all applications of ionic liquids and ionogels. For the $\mathrm{Cl}^{-}$containing ionic liquid, addition of $\mathrm{Zn}$ improved thermal stability ( $T_{\text {onset }}$ increased by 54 ${ }^{\circ} \mathrm{C}$ ) because $\mathrm{Cl}^{-}$anions were coordinated to the metal in the $\left[\mathrm{ZnCl}_{4}\right]^{2-}$ complex and therefore not able to act as nucleophiles in retro $\mathrm{S}_{\mathrm{N}} 2$ reactions - the dominant decomposition process for halide ionic liquids. ${ }^{38}$ Lower quantities of $\mathrm{Zn}$ (i.e. $\chi=0.1$ ) had similar thermal stabilities to those of [omim]Cl because free $\mathrm{Cl}^{-}$was still present (in a mixture with $\left.\left[\mathrm{ZnCl}_{4}\right]^{2-}\right)^{39}$ and thus able to participate in retro $\mathrm{S}_{\mathrm{N}} 2$ reactions. The corresponding $\mathrm{Cl}^{-}$ ionogels had thermal stabilities that reflected the stabilities of their respective ionic liquids (ESI, Fig. $\mathrm{S} 45 \dagger$ ), which showed that thermal stability of ionogels is largely determined by the identity of the ionic liquid anion. For the [omim $]\left[\mathrm{NTf}_{2}\right]$ ionic liquid, addition of $\mathrm{Zn}$ slightly reduced the thermal stability of the ionic liquid ( $T_{\text {onset }}$ reduced by $45^{\circ} \mathrm{C}$ ), but $T_{\text {onset }}$ was $70{ }^{\circ} \mathrm{C}$ higher than analogous [omim] $\mathrm{Cl}_{-}{ }_{0.33} \mathrm{ZnCl}_{2}$ because of the intrinsic thermal stability of the non-nucleophilic $\left[\mathrm{NTf}_{2}\right]^{-}$anion (ESI, Fig. S46†). ${ }^{40}$ However, thermal stability of the $[\mathrm{omim}]\left[\mathrm{NTf}_{2}\right]-{ }_{0.33} \mathrm{Zn}\left[\mathrm{NTf}_{2}\right]_{2}$ ionogel with $30 \%$ PEGDA was significantly compromised when compared to the $\mathrm{Zn}$ free ionogel analogue ( $T_{\text {onset }}$ reduce by 173 $\left.{ }^{\circ} \mathrm{C}\right)$. Furthermore, reducing the quantity of $\mathrm{Zn}$ did not improve thermal stability, and even small quantities of $\mathrm{Zn}($ i.e., $\chi=0.05)$ significantly impacted ionogel thermal stability (ESI, Fig. S47†). These observations highlighted that association of metals to coordinating PEGDA polymer phases introduced new thermal 
decomposition pathways. Further investigation into metal containing ionic liquid and ionogel thermal properties are currently underway in our laboratory because of a significant lack of literature data.

\section{Conclusions}

In this work we have prepared new metal ionogels and characterised their surfaces with two complimentary techniques - XPS and SIMS. Involatile ionic liquids open up the possibility of studying gel surfaces with UHV-based techniques, which is impossible for other types of gels with volatile liquid phases. Our surface measurements revealed that ionic liquid anion coordination strength affected whether $\mathrm{Zn}$ remained in the liquid phase, and thus at the surface, or whether it coordinated to PEGDA instead, which gave a surface devoid of metal. Consequently, the mechanical properties of ionogels could be manipulated by either reducing the hydrogen bond acceptor ability of the anion to increase strength, or by disrupting the uniform polymer network via templating to decrease strength. The competitive coordination of anions and polymers to $\mathrm{Zn}$ was the underlying principle that introduced the two processes. Lewis acidic metal complexes favoured polymer coordination, while Lewis basic complexes were stable in the presence of coordinating polymer. The molecular level understanding provided in this work was only possible because of the unique properties of ionic liquids, which open up new avenues for gel based materials.

Here, most experiments were performed with Zn but supporting data for Co showed that the metal ion could be readily substituted. This indicated that the process was applicable to a broad range of emerging applications that could benefit from interfacially and mechanically tunable metal ionogels. Examples of emerging applications include electrochemical devices based on ionogel electrolytes, where the flexibility and conductivity of ionogels enable flexible energy storage devices, sensors, and actuators. Speciation of metals and interfacial properties of soft electrolytes are particularly important for electrochemical applications where gels interface with electrodes. Other examples include biomedical appliances, where soft gels must interface with delicate biomaterials that require surfaces free of toxic metals, and catalytic membranes or supports, where speciation and surface concentration can directly influence catalytic performance. Therefore, surface chemistry is of critical importance for applications where gels interface with other materials or chemicals, and molecular level insights in the bulk and at surfaces of gels provide valuable information for all applications of ionogels. Importantly, metal salts create a new way to fine-tune surface composition and mechanical properties of ionogels across a broad design space to target application requirements.

\section{Conflicts of interest}

There are no conflicts to declare.

\section{Acknowledgements}

JPH, CJC, and APSB would like to thank EPSRC (EP/K038648/1) for funding. RPM would like to thank the Daphne Jackson Trust for awarding him a Daphne Jackson Fellowship - jointly funded by the Royal Society of Chemistry and the Royal Academy of Engineering. CJC would like to thank HarwellXPS for access to the Thermo Scientific Theta Probe, and Prof. Robert Palgrave for helpful advice with data acquisition and analysis. We also thank Dr Sarah Fearn for help with SIMS acquisition and analysis, and Dr Ruth Brooker for access to the Instron 5543. Computational resources provided by the Imperial College Research Computing Service (DOI: 10.14469/hpc/2232) are gratefully acknowledged.

\section{Notes and references}

1 P. C. Marr and A. C. Marr, Green Chem., 2015, 18, 105-128.

2 C. J. Clarke, W. C. Tu, O. Levers, A. Bröhl and J. P. Hallett, Chem. Rev., 2018, 118, 747-800.

3 J. Le Bideau, L. Viau and A. Vioux, Chem. Soc. Rev., 2011, 40, 907-925.

4 Y. Ren, J. Guo, Z. Liu, Z. Sun, Y. Wu, L. Liu and F. Yan, Sci. Adv., 2019, 5, eaax0648.

5 X. Liu, Z. Wen, D. Wu, H. Wang, J. Yang and Q. Wang, J. Mater. Chem. A, 2014, 2, 11569-11573.

6 Y. Zhong, G. T. M. Nguyen, C. Dric Plesse, F. Dé Ric Vidal and E. W. H. Jager, J. Mater. Chem. C, 2019, 256, 256.

7 Ionic Liquids in Synthesis, ed. P. Wasserscheid and T. Welton, Wiley-VCH Verlag GmbH \& Co. KGaA, Weinheim, Germany, 2007.

8 L. Viau, C. Tourné-Péteilh, J. M. Devoisselle and A. Vioux, Chem. Commun., 2010, 46, 228-230.

9 H. Y. Lee, Y. Cai, S. Velioglu, C. Mu, C. J. Chang, Y. L. Chen, Y. Song, J. W. Chew and X. M. Hu, Chem. Mater., 2017, 29, 6947-6955.

10 J. Sun, Y. Yuan, G. Lu, L. Li, X. Zhu and J. Nie, J. Mater. Chem. C, 2019, 7, 11244-11250.

11 A. P. S. Brogan, C. J. Clarke, A. Charalambidou, C. N. Loynachan, S. E. Norman, J. Doutch and J. P. Hallett, Mater. Horiz., 2020, 7, 820-826.

12 C. J. Clarke, S. Maxwell-Hogg, E. F. Smith, R. R. Hawker, J. B. Harper and P. Licence, Phys. Chem. Chem. Phys., 2019, 21, 114-123.

13 J. Estager, J. D. Holbrey and M. Swadźba-Kwaśny, Chem. Soc. Rev., 2014, 43, 847-886.

14 P. Wasserscheid and W. Keim, Angew. Chem., Int. Ed. Engl., 2000, 39, 3772-3789.

15 K. Li, H. Choudhary and R. D. Rogers, Current Opinion in Green and Sustainable Chemistry, 2018, 11, 15-21.

16 O. Bortolini, C. Chiappe, T. Ghilardi, A. Massi and C. S. Pomelli, J. Phys. Chem. A, 2015, 119, 5078-5087.

17 F. Billeci, H. Q. N. Gunaratne, F. D'Anna, G. G. Morgan, K. R. Seddon and N. V. Plechkova, Green Chem., 2019, 21, 1412-1416.

18 T. Watkins, A. Kumar and D. A. Buttry, J. Am. Chem. Soc., 2016, 138, 641-650. 
19 T. Terashima, M. Kawabe, Y. Miyabara, H. Yoda and M. Sawamoto, Nat. Commun., 2013, 4, 2321.

20 J. Hou, A. F. Sapnik and T. D. Bennett, Chem. Sci., 2020, 11, 310-323.

21 A. V Zhukhovitskiy, M. Zhong, E. G. Keeler, V. K. Michaelis, J. E. P. Sun, M. J. A. Hore, D. J. Pochan, R. G. Griffin, A. P. Willard and J. A. Johnson, Nat. Chem., 2016, 8, 33-41.

22 A. W. Taylor, S. Men, C. J. Clarke and P. Licence, RSC Adv., 2013, 3, 9436.

23 M. Busato, P. D'Angelo, A. Lapi, M. Tolazzi and A. Melchior, J. Mol. Liq., 2020, 299, 112120.

24 Y. Zhuo, S. Xiao, V. Håkonsen, J. He and Z. Zhang, ACS Mater. Lett., 2020, 616-623.

25 K. R. J. Lovelock, I. J. Villar-Garcia, F. Maier, H. P. Steinrück and P. Licence, Chem. Rev., 2010, 110, 5158-5190.

26 I. J. Villar-Garcia, E. F. Smith, A. W. Taylor, F. Qiu, K. R. J. Lovelock, R. G. Jones and P. Licence, Phys. Chem. Chem. Phys., 2011, 13, 2797-2808.

27 D. R. Baer, K. Artyushkova, H. Cohen, C. D. Easton, M. Engelhard, T. R. Gengenbach, G. Greczynski, P. Mack, D. J. Morgan and A. Roberts, J. Vac. Sci. Technol., A, 2020, 38, 031204.

28 A. F. M. Cláudio, L. Swift, J. P. Hallett, T. Welton, J. A. P. Coutinho and M. G. Freire, Phys. Chem. Chem. Phys., 2014, 16, 6593-6601.

29 F. Maier, T. Cremer, C. Kolbeck, K. R. J. Lovelock, N. Paape, P. S. Schulz, P. Wasserscheid and H.-P. Steinrück, Phys. Chem. Chem. Phys., 2010, 12, 1905.
30 H. Rodríguez, M. Francisco, M. Rahman, N. Sun and R. D. Rogers, Phys. Chem. Chem. Phys., 2009, 11, 1091610922.

31 J. Estager, J. D. Holbrey and M. Swadźba-Kwaśny, Chem. Soc. Rev., 2014, 43, 847-886.

32 F. Sessa, V. Migliorati, A. Serva, A. Lapi, G. Aquilanti, G. Mancini and P. D'Angelo, Phys. Chem. Chem. Phys., 2018, 20, 2662-2675.

33 C. J. Clarke, L. Bui-Le, P. J. Corbett and J. P. Hallett, Ind. Eng. Chem. Res., 2020, 59, 12536-12544.

34 M. A. Ab Rani, A. Brant, L. Crowhurst, A. Dolan, M. Lui, N. H. Hassan, J. P. Hallett, P. A. Hunt, H. Niedermeyer, J. M. Perez-Arlandis, M. Schrems, T. Welton and R. Wilding, Phys. Chem. Chem. Phys., 2011, 13, 16831-16840.

35 P. A. Hunt, C. R. Ashworth and R. P. Matthews, Chem. Soc. Rev., 2015, 44, 1257-1288.

36 T. Ueki, Polym. J., 2014, 46, 646-655.

37 R. P. Matthews, I. J. Villar-Garcia, C. C. Weber, J. Griffith, F. Cameron, J. P. Hallett, P. A. Hunt and T. Welton, Phys. Chem. Chem. Phys., 2016, 18, 8608-8624.

38 C. Maton, N. De Vos and C. V Stevens, Chem. Soc. Rev., 2013, 42, 5963-5977.

39 C. J. Clarke, S. Hayama, A. Hawes, J. P. Hallett, T. W. Chamberlain, K. R. J. Lovelock and N. A. Besley, J. Phys. Chem. A, 2019, 123, 9552-9559.

40 C. J. Clarke, L. Bui-Le, J. P. Hallett and P. Licence, ACS Sustainable Chem. Eng., 2020, 8, 8762-8772. 